\section{A) Check for updates}

Cite this: Polym. Chem., 2019, 10 1585

Received 7th January 2019, Accepted 7th February 2019

DOI: 10.1039/c9py00022d rsc.li/polymers

\title{
Visible-light-mediated, additive-free, and open-to-air controlled radical polymerization of acrylates and acrylamides $\uparrow$
}

\author{
Jessica R. Lamb, (iD K. Peter Qin (iD) and Jeremiah A. Johnson (ID *
}

\begin{abstract}
Oxygen tolerance in controlled radical polymerizations has been an active field of study in recent years. Herein, we report a photocontrolled, additive-free iniferter polymerization that operates in completely open vials utilizing the "polymerizing through oxygen" mechanism. Trithiocarbonates are directly activated with high intensity $450 \mathrm{~nm}$ light to produce narrowly dispersed $\left(M_{w} / M_{n}=1.1-1.6\right)$ polyacrylates and polyacrylamides. Living behavior is demonstrated through chain extension, block copolymer synthesis, and control over molecular weight through varying the monomer : iniferter ratio. A slight increase in induction period is observed for the open vial polymerization compared to the air-free reaction, but polymers with similar $M_{n}$ and $M_{w} / M_{n}$ values are produced after 30-60 minutes of irradiation. This system will provide a convenient platform for living additive manufacturing because of its fast reaction time, air tolerance, wide monomer scope, and lack of any additives beyond the monomer, iniferter, and DMSO solvent.
\end{abstract}

\section{Introduction}

Controlled radical polymerization (CRP) techniques have transformed macromolecular synthesis by enabling access to polymers with controlled molecular weights, narrow molecular weight distributions, and well-defined architectures..$^{1-3}$ Photocontrolled CRP (photo-CRP) affords the additional benefits of spatiotemporal control by using light as a low cost external stimulus. Light-induced free radical polymerizations have already found commercial use in photolithography, additive manufacturing, and for the synthesis of coatings, adhesives, and resins; however, most of these systems do not have "living" characteristics, such as chain-end fidelity and the ability to reinitiate over several cycles. ${ }^{4}$

Our group recently combined the concepts of light-induced additive manufacturing ${ }^{5}$ and photo-CRP ${ }^{6}$ to achieve "living additive manufacturing" (LAM) in which a dormant parent polymer network can be subsequently altered to produce complex, responsive daughter materials. ${ }^{7}$ One downside of our reported LAM system - and most radical polymerizations - is oxygen inhibition due to trapping of propagating carbon-centered radicals by oxygen, which produces peroxy radicals. ${ }^{8,9}$ This deactivation is

Department of Chemistry, Massachusetts Institute of Technology,

77 Massachusetts Avenue, Cambridge, Massachusetts 02139, USA.

E-mail:jaj2109@mit.edu

$\dagger$ Electronic supplementary information (ESI) available: Materials, experimental procedures, characterization methods, expanded data tables and figures. See DOI: $10.1039 / \mathrm{c} 9$ py00022d generally avoided by performing the polymerizations under inert conditions; however, degassing techniques such as freezepump-thaw cycles, sparging, or performing experiments in a glovebox can be impractical for certain applications.

We set out to develop a second-generation LAM system that did not require any degassing procedures and could ideally be done fully open to air (to mimic a benchtop 3D printer) on a reasonably fast time scale. Before we can achieve this goal, an efficient oxygen tolerant photo-CRP is required. Oxygen tolerant CRP reactions have garnered significant interest in recent years (Fig. 1A-C).$^{10}$ In many cases, a sacrificial compound is added to scrub the oxygen or regenerate a catalyst that can react with and effectively remove oxygen. ${ }^{11,12}$ In other cases, no specific scrubbing mechanism is employed; oxygen simply reacts with excess radicals in the system, referred to as "polymerizing through oxygen" (Fig. 2, red path). ${ }^{13,14}$

For photo-CRP utilizing common RAFT agents as iniferters, the current best systems for achieving oxygen tolerance involve photoredox catalysts - such as $\operatorname{Ir}(\text { ppy })_{3},{ }^{15,16} \mathrm{Ru}(\text { bpy })_{3} \mathrm{Cl}_{2},{ }^{17}$ eosin $\mathrm{y},{ }^{18}$ and zinc tetraphenylporphyrin $(\mathrm{ZnTPP})^{19,20}$ - converting triplet oxygen into a reactive species (such as singlet oxygen) that can be trapped. These techniques rely on highly colored dyes or metal catalysts, which can be difficult to remove from the final materials. In addition, most of these systems still operate in a closed vial such that the amount of oxygen is finite; it is generally proposed that the oxygen in both the solution and the headspace is scrubbed during the long induction period before photopolymerization can begin. A few reports describe exceptions where polymerizations in 
Previous Work: Oxygen tolerant systems for photocontrolled iniferter polymerization

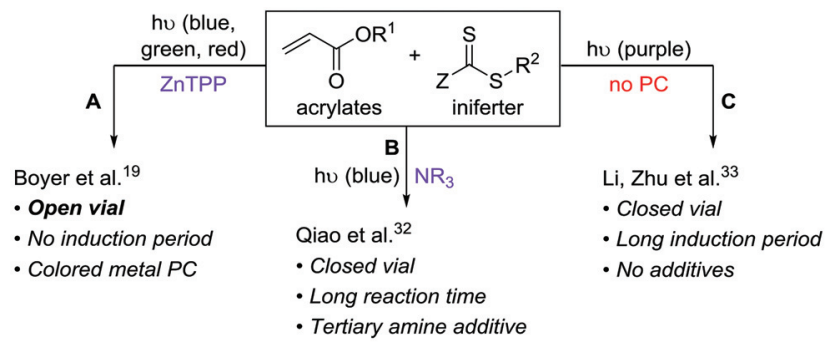

D This Work: Open vial polymerization with no additives

Fig. 1 Progression of oxygen tolerant CRP using visible light and thiocarbonylthio iniferters: (A) Photocatalyst-mediated CRP in a completely open vial using a metal catalyst. (B) Tertiary amines as sacrificial reductants in photocatalyst-free CRP. (C) Additive-free CRP in a closed vial. (D) Additive-free, open vial CRP utilizing high light intensity.

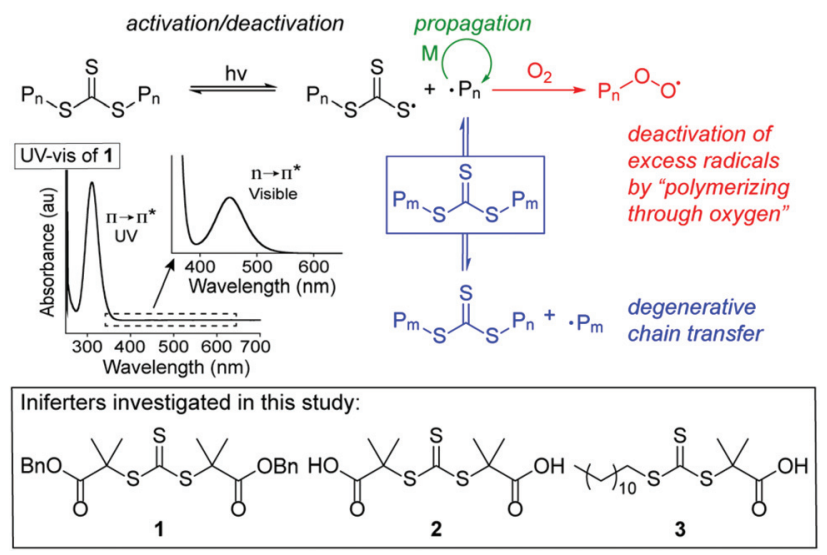

Fig. 2 Mechanism of trithiocarbonates (TTC)-mediated iniferter polymerization and structures of iniferters used in this study.

completely open vials are possible, including methyl acrylate polymerization in DMSO using $\mathrm{ZnTPP}^{19}$ (Fig. 1A) and acrylic acid polymerization in water using a combination of fluorescein and ascorbic acid. ${ }^{21}$

To avoid additional purification to remove highly colored and/or metal photocatalysts, significant work has been done to directly photolyze thiocarbonylthio compounds, such as xanthates and trithiocarbonates (TTCs), for photo-CRP (Fig. 2, black path). ${ }^{22-24}$ Initially, UV light was utilized due to the large $\pi$ to $\pi^{*}$ transition of the $\mathrm{C}=\mathrm{S}$ bond. This approach can lead to irreversible decomposition of the iniferter and the selfinitiation of monomers. ${ }^{22,25,26}$ Recently, increased control over such iniferter polymerizations has been gained by using low intensity long wavelength UV/violet light ${ }^{27,28}$ and visible (blue or green) light, ${ }^{29-31}$ the latter operating via the spin-forbidden $\mathrm{n}$ to $\pi^{*}$ pathway. While these systems resulted in well-controlled polymerizations, many are quite slow due to the low extinction coefficient of the $\mathrm{n}$ to $\pi^{*}$ transition and most were done under inert atmosphere.

Qiao and coworkers achieved oxygen tolerance without a photocatalyst by using tertiary amines as sacrificial reductants for both oxygen scrubbing and photoredox polymerization (Fig. 1B). ${ }^{32}$ While this system demonstrated excellent control over molecular weight and was effective for the synthesis of block copolymers through chain extension, it was performed in a closed vial and required multiple hours to days of irradiation to yield high molecular weight polymers. Li, Zhu, and coworkers reported a very fast (5-20 min) polymerization of $n$-butyl acrylate using $390 \mathrm{~nm}$ light under air-free conditions; however, when performed in a non-degassed, sealed vessel, the polymerization had a 110 min induction period (Fig. 1C). ${ }^{33}$

Despite these recent advances, our goals for LAM would be ideally served by a fast photo-CRP that displays living characteristics and can operate under open conditions without highly colored photocatalysts. Here, we report an open-vial polymerization with direct iniferter activation using blue $(450 \mathrm{~nm})$ light on a reasonably fast timescale $(1 \mathrm{~h})$. This additive-free photoCRP provides polymers with narrow molecular weight distributions, linear molecular weight growth with conversion, and chain end fidelity, which allows for chain extension (Fig. 1D).

\section{Results and discussion}

\section{Optimization and monomer scope}

Inspired by the open vial polymerization achieved by Boyer and coworkers using ZnTPP, ${ }^{19}$ we began to pursue open to air polymerizations using symmetrical TTC 1 (Fig. 2) with various photocatalysts in our custom-built photoreactor (see ESI, $\uparrow$ for photoreactor details). ${ }^{34}$ A serendipitous discovery was made when we ran control experiments for the open vial polymerization under red $(625 \mathrm{~nm})$, green $(530 \mathrm{~nm})$ and blue $(450 \mathrm{~nm})$ light (Table 1, entries 1-3): under $450 \mathrm{~nm}$ light in the absence of a photocatalyst, methyl acrylate (MA) could be polymerized in a completely open vial in 1 hour (entry 3 ). The unstirred

Table 1 Discovery and partial optimization of the open vial polymerization of methyl acrylate (MA) (an extended Table 1 can be found in the ESI, Table S2) ${ }^{a}$

\begin{tabular}{lllllll}
\hline & $\begin{array}{l}\lambda \\
\text { Entry } \\
(\mathrm{nm})\end{array}$ & $\begin{array}{l}\mathrm{MA}: \mathrm{DMSO} \\
(\mathrm{v}: \mathrm{v}, \mu \mathrm{l})\end{array}$ & $\begin{array}{l}\mathrm{Conv} . \\
(\%)\end{array}$ & $\begin{array}{l}M_{\mathrm{n}, \mathrm{GPC}} \\
\left(\mathrm{kg} \mathrm{mol}^{-1}\right)\end{array}$ & $\begin{array}{l}M_{\mathrm{w}, \mathrm{GPC}} \\
\left(\mathrm{kg} \mathrm{mol}^{-1}\right)\end{array}$ & $M_{\mathrm{w}} / M_{\mathrm{n}}$ \\
\hline 1 & 625 & $250: 250$ & $<1$ & - & - & - \\
2 & 530 & $250: 250$ & $<1$ & - & - & - \\
3 & 450 & $250: 250$ & 98 & 13.25 & 15.03 & 1.13 \\
4 & 450 & $500: 0$ & 55 & 7.45 & 9.30 & 1.25 \\
5 & 450 & $400: 100$ & 74 & 12.78 & 15.23 & 1.19 \\
6 & 450 & $325: 175$ & 85 & 11.95 & 14.78 & 1.24 \\
7 & 450 & $250: 250$ & 83 & 13.75 & 15.85 & 1.15 \\
8 & 450 & $175: 325$ & 81 & 12.37 & 15.51 & 1.26 \\
9 & 450 & $100: 400$ & 31 & 5.84 & 8.58 & 1.47
\end{tabular}

${ }^{a}$ Conditions: MA:TTC (200:1), $0.5 \mathrm{ml}$ scale, $60 \mathrm{~min}$ (entries 1-3), $45 \mathrm{~min}$ (entries $4-9$ ), uncapped 1 dram vial, no stirring. ${ }^{b}$ Conversion is uncorrected for monomer evaporation. 
polymerization in DMSO reached high conversion and yielded polymer products with a narrow molar mass distribution. In contrast to Boyer's system, in which the oxygen tolerance is proposed to originate from the ZnTPP, ${ }^{20}$ we hypothesized that our system relies on a polymerizing through oxygen mechanism, which could explain the presence of a small low molecular weight tail in the GPC trace (Fig. S7, $\dagger$ see the mechanism section for further discussion on the origin of oxygen tolerance in this system).

We began to probe this reaction by varying the monomer concentration at a fixed MA: TTC ratio of 200:1 (Table 1, entries 4-9). Not only does the concentration affect the rate of polymerization, but the iniferter concentration also dictates the radical flux, which is known to require a certain threshold to successfully employ the polymerizing through oxygen strategy. ${ }^{10,13}$ Bulk polymerization (entry 4 ) and dilute polymerization ( 2.2 M, entry 9) both resulted in lower molar masses and bimodal molar mass distributions. All of the intermediate concentrations (entries 5-8) resulted in similar $M_{\mathrm{w}}$ values, with the $M_{\mathrm{n}}$ and dispersity differences arising from the slight changes in the low molecular weight tail (see Fig. S8 $\dagger$ for GPC traces). A 1:1 ratio between monomer and solvent was used going forward. Other solvents were tested (Table S2, $\dagger$ entries 10-14), but toluene, ethyl acetate, acetone, and acetonitrile all resulted in no polymerization under standard conditions. $N, N$-Dimethylformamide did yield some polymer $\left(M_{\mathrm{w}} / M_{\mathrm{n}}=1.19\right)$ after $1 \mathrm{~h}$ of irradiation, but the molar mass was significantly reduced $\left(M_{\mathrm{n}}=3.77 \mathrm{~kg} \mathrm{~mol}^{-1}\right.$, Table S2, $\dagger$ entry 13). Solvent mixtures between DMSO and MeCN (Table S2, $\dagger$ entries 15-17) could be used successfully, but the polymer molecular weight quickly drops if the DMSO fraction is below $\sim 80 \%$.

The reaction was then run on different scales $(0.2-0.6 \mathrm{ml}$, Table S2, entries 18-22 and Fig. S9†) in a 1 dram vial which revealed that a reaction volume of at least $0.4-0.5 \mathrm{ml}$ is needed for this setup to achieve well-controlled and high molecular weight polymers (vide infra). We chose $0.5 \mathrm{ml}$ as the standard reaction volume for MA. Next, the effect of the iniferter was probed by using the commercially available TTCs 2 and 3 (Table S2, $\dagger$ entries 23 and 24). 2 is similarly symmetrical to $\mathbf{1}$, but is terminated by two carboxylic acids instead of benzyl esters. Under standard conditions, 2 yields polymer with slightly lower molar mass $\left(M_{\mathrm{n}}=12.22 \mathrm{~kg} \mathrm{~mol}^{-1}\right)$ and higher dispersity (1.26) (entry 23). The unsymmetrical TTC 3 was less effective, providing $6.51 \mathrm{~kg} \mathrm{~mol}^{-1}$ polymer with a dispersity of 1.36 in 1 hour (entry 24). These data indicate that further optimization will be needed when changing the iniferter for open vial polymerizations, a potential drawback when compared to oxygen-tolerant systems utilizing a photocatalyst. ${ }^{19}$

Finally, the efficacy of the polymerization was shown to be strongly dependent on the use of high light intensity (Fig. 3A and Table S2, $\dagger$ entries 25-29); however, the effect was somewhat dependent on the monomer investigated (Fig. S10†). ${ }^{34}$ We hypothesize that the high light intensity is necessary both to achieve high radical flux for the polymerizing through oxygen mechanism ${ }^{13}$ and for the accelerated polymerization
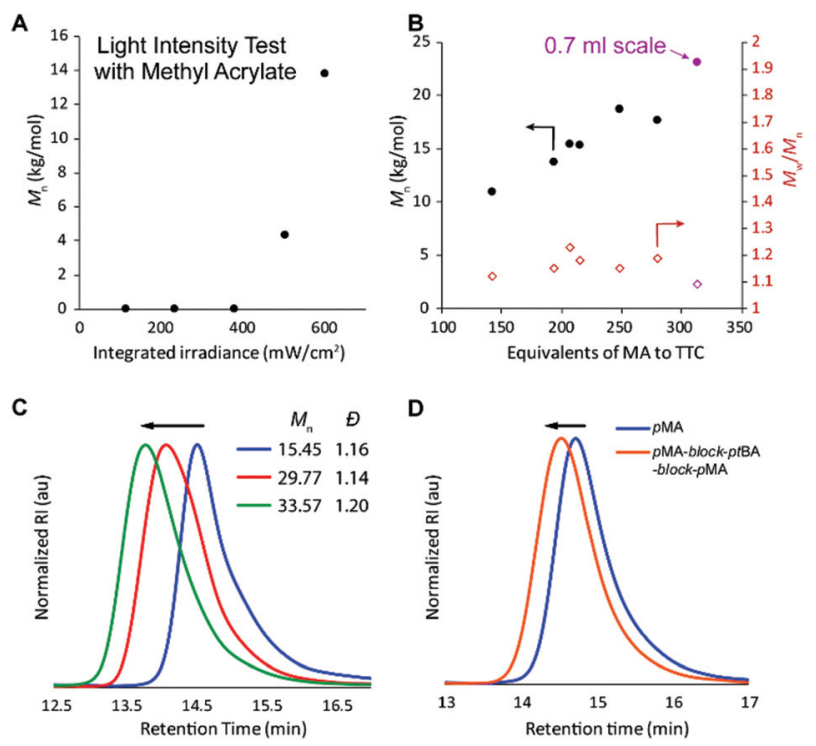

Fig. 3 (A) Molecular weight dependence on light intensity. (B) Molecular weight and dispersity changes with MA : TTC ratio. (C) GPC traces of chain extension from precipitated pMA to form pseudoblocks. (D) GPC traces of block copolymer synthesis.

rate $^{35}$ compared to many previous systems ${ }^{29,30}$ that have directly activated the $\mathrm{n}$ to $\pi^{*}$ transition of the iniferter.

After understanding which variables affect the polymerization, different monomer: TTC ratios were used to demonstrate that molar mass increases approximately linearly until ca. $250: 1$, at which point the molar mass achieved in 1 hour levels off (Fig. 3B and Table S3, $\dagger$ entries 1-6). We initially thought that perhaps the polymerization rate was limiting the molar mass that could be achieved within 60 minutes of irradiation, but increasing the polymerization time to 90 or 120 minutes resulted in bimodal molar mass distributions and slightly lower $M_{\mathrm{n}}$ (Table S3, † entries 7 and 8). We attribute this degradation to chains near the solution-air interface reacting with oxygen (red path, Fig. 2), resulting in chains with half of the molar mass compared to the original polymer. Increasing the reaction volume to $0.7 \mathrm{ml}$ led to an increased molar mass (purple point in Fig. 3B and Table S3, $\dagger$ entry 9), though all reactions with high monomer:iniferter ratios $(\sim 300: 1)$ were fairly inconsistent and sometimes resulted in bimodal distributions. The inconsistency is likely due to the low TTC concentration, which is known to reduce control in TTC-mediated iniferter polymerizations. ${ }^{27}$

A variety of other acrylate and acrylamide monomers can be polymerized in fully open vials under these conditions (Table 2). $n$-Butyl acrylate ( $n \mathrm{BA})$ required a slightly larger reaction volume, but proceeded with similar control as MA (entry 1). $t$-Butyl acrylate ( $t \mathrm{BA})$ resulted in polymer with slight highmolecular-weight tailing but also showed good control over molar mass by varying the equivalents of monomer to iniferter (entries $2-4$ and Fig. S12 $\dagger$ ). Poly $(t \mathrm{BA})$ is of particular interest because it can be deprotected to form poly(acrylic acid) (PAA), 
Table 2 Open vial polymerization using other acrylate and acrylamide monomers ${ }^{a}$

\begin{tabular}{|c|c|c|c|c|c|c|c|c|}
\hline Entry & Monomer & Monomer : TTC $^{b}$ & $\begin{array}{l}\text { Monomer : DMSO } \\
(\mathrm{v}: \mathrm{v}, \mu \mathrm{l})\end{array}$ & $\begin{array}{l}\text { Conv. }{ }^{c} \\
(\%)\end{array}$ & $\begin{array}{l}M_{\mathrm{n}}, \text { Theo } \\
\left(\mathrm{kg} \mathrm{mol}^{-1}\right)\end{array}$ & $\begin{array}{l}M_{\mathrm{n}, \mathrm{GPC}} \\
\left(\mathrm{kg} \mathrm{mol}{ }^{-1}\right)\end{array}$ & 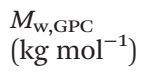 & $M_{\mathrm{w}} / M_{\mathrm{n}}$ \\
\hline 1 & $n$-Butyl-acrylate & $200: 1$ & $350: 350$ & 65 & 17.23 & 20.40 & 24.18 & 1.19 \\
\hline 2 & $t$-Butyl acrylate & $150: 1$ & $300: 300$ & 68 & 13.25 & 15.21 & 18.79 & 1.24 \\
\hline 3 & $t$-Butyl acrylate & $200: 1$ & $300: 300$ & 62 & 16.05 & 17.97 & 21.96 & 1.22 \\
\hline 4 & $t$-Butyl acrylate & $250: 1$ & $300: 300$ & 66 & 21.32 & 20.53 & 26.37 & 1.29 \\
\hline 5 & 2-(2-Ethoxyethoxy)ethyl acrylate & $200: 1$ & $300: 300$ & 59 & 21.78 & 38.01 & 58.16 & 1.53 \\
\hline $6^{d}$ & Methyl methacrylate & $200: 1$ & $325: 175$ & $33^{e}$ & 6.66 & 28.00 & 42.93 & 1.53 \\
\hline 7 & $N, N$-Dimethyl acrylamide & $200: 1$ & $400: 300$ & $41^{e}$ & 8.40 & 16.11 & 27.25 & 1.69 \\
\hline 8 & $N$-Isopropyl acrylamide & $200: 1$ & $440: 350^{f}$ & 53 & 12.26 & 13.16 & 20.82 & 1.58 \\
\hline 9 & Acrylamide & $200: 1$ & $274: 400^{f}$ & 55 & 8.07 & 14.18 & 16.23 & 1.15 \\
\hline
\end{tabular}

${ }^{a}$ Conditions: Monomer : TTC (200:1), 60 min, uncapped 1 dram vial, no stirring. ${ }^{b}$ Molar ratio. ${ }^{c}$ Conversion is corrected for monomer evaporation. ${ }^{d} 30 \mathrm{~min} .{ }^{e}$ Conversion not corrected for monomer evaporation. ${ }^{f}$ Solid monomer so concentration listed as weight (mg) : volume $(\mu \mathrm{l})$.

a polyelectrolyte that is commonly used as a super-absorbing polymer and as a coating for biomedical applications. ${ }^{36-38} \mathrm{~A}$ sample of poly $(t \mathrm{BA})$ was deprotected to PAA with trifluoroacetic acid as a proof of concept. ${ }^{34}$ The solubility properties and ${ }^{1} \mathrm{H}$ NMR analysis (Fig. S3 versus Fig. S5 $\dagger$ ) indicated clean conversion to PAA. This completely metal-free synthesis of PAA avoids additional purification steps to remove any catalysts or additives that could contaminate the material.

2-(2-Ethoxyethoxy)ethyl acrylate (DEGA), methyl methacrylate (MMA), $N, N$-dimethylacrylamide (DMAA), and $N$-isopropyl acrylamide (NiPAAm) were all successfully polymerized in the open vial setup, but with less control under standard conditions (entries 5-8 and Fig. S13 $\dagger$ ). DEGA and NiPAAm resulted in generally broader molar mass distributions, while DMAA had a narrow main distribution with a pronounced low molecular weight tail. MMA reached very high molar mass at low conversion, which could be due to fast propagation relative to initiation or slower chain transfer. Acrylamide was polymerized with a narrow dispersity, similar to MA (entry 9). All molecular weights were larger than the theoretical values, presumably due to partial degradation of the iniferter through reactions with oxygen (red path, Fig. 2).

To prove that the iniferter was still active at the end of the polymerization, more monomer was added followed by an additional hour of irradiation, resulting in chain extension without a loss of control (Fig. S15 $\dagger$ ). If no extra monomer was added, the molecular weight did not change between 1 and 2 hours of irradiation. Additionally, pMA macro-iniferter was isolated by precipitation into cold hexanes before performing additional growth experiments. Over two reinitiation cycles, the GPC traces maintained a narrow, monomodal distribution and clearly shifted to shorter retention times (Fig. 3C). Following a similar procedure, a triblock copolymer of pMA-block-ptBAblock-pMA was prepared with excellent control (Fig. 3D).

\section{Mechanistic investigations/origin of oxygen tolerance}

To confirm that the polymerization was due to the visible light photolysis of the TTC, a series of control experiments were performed. A dry ice-acetone bath was used to continually cool the reactor during the polymerization, but the reaction solu- tions do reach $60{ }^{\circ} \mathrm{C}$ due to the exotherm of the polymerization. While this is still an elevated temperature, compared to the thermally-initiated, open-to-air RAFT polymerization, ${ }^{13}$ temperatures above $100{ }^{\circ} \mathrm{C}$ are not required to generate the requisite high radical flux needed to achieve oxygen tolerance. Notably, control reactions heated to 40,60 , and $80{ }^{\circ} \mathrm{C}$ in the dark resulted in no conversion (Table S4, $\dagger$ entries $1-3$ ). These results are also supported by our initial finding that, of the visible wavelengths tested, only blue light is able to activate the TTC (Table 1, entries 1-3) since TTC 1 has a $\lambda_{\max , \mathrm{n} \rightarrow \pi^{*}}=$ $452 \mathrm{~nm}$. During the initialization period when the first monomers are inserted into the iniferter $\mathrm{C}-\mathrm{S}$ bonds, the $\mathrm{n}$ to $\pi^{*}$ transition slightly blue shifts to $\lambda_{\max , \mathrm{n} \rightarrow \pi^{*}}=428 \mathrm{~nm}$, but still overlaps sufficiently with the emission of the LED to induce photolysis (see Fig. S28†). If no TTC was added to the reaction, no conversion was observed (Table S4, $\uparrow$ entry 4), corroborating Qiao's observation that visible light does not induce selfpolymerization of the monomer. ${ }^{29}$

We hypothesize that our system displays oxygen tolerance through a combination of high viscosity, low oxygen solubility, high irradiance, bottom irradiation, no stirring, and large reaction scale. These factors synergize so that the little oxygen that is present in the solution can be removed through the polymerizing through oxygen mechanism and oxygen mass transport from the air is limited. This proposal is supported by our optimization reactions and a variety of other control experiments. We hypothesize that DMSO is the best solvent due to its high viscosity ${ }^{39}$ and low solubility of oxygen ${ }^{40}$ compared to the other solvents. The reaction volume screen (vide supra, Table S2, $\uparrow$ entries 18-22) indicated that there is a minimum reaction volume required to achieve controlled polymerization. Reaction volume affects oxygen diffusion by changing the surface-area/volume ratio ${ }^{41}$ and by spatially separating the oxygen in the air from the propagating radicals near the light source. If the reaction is stirred, which increases the mass transport of oxygen, no polymerization is observed (Table $S 4, \dagger$ entry 5). It is worthy to note that the polymerization proceeds with excellent control under optimized conditions despite any potential inhomogeneities caused by lack of stirring. This control can possibly be attributed to the 
degenerative chain transfer of the RAFT process. This finding will be important for the application of this method to LAM because stirring is not employed when forming crosslinked polymer networks, but according to these data, living behavior should be maintained. The penetration depth of the light will also affect the maximum depth of the reaction, such that scaling up the reaction must be done by increasing volume laterally. This hypothesis was tested by running a $2 \mathrm{ml}$ reaction in an uncapped $20 \mathrm{ml}$ scintillation vial (Table S4, $\dagger$ entry 6). Comparable molar mass $\left(M_{\mathrm{n}}=15.09 \mathrm{~kg} \mathrm{~mol}^{-1}\right)$ and dispersity (1.16) values were obtained as on the smaller scale.

Many oxygen tolerant systems require a scrubbing mechanism in which all of the oxygen in a closed vial, both in the solution and in the headspace, is removed before the polymerization can proceed, often resulting in long induction periods. ${ }^{15,17,33}$ In an open vial system, the headspace is effectively infinite, such that all of the oxygen can never be purged. Therefore, for solutions that have not been degassed, the polymerization should not be drastically affected by a cap, besides the amount of monomer evaporation. This hypothesis was tested by running parallel reactions with different headspaces: one uncapped vial, one with a closed cap and vent needle, and one closed vial (Table $\mathrm{S} 4, \dagger$ entries 7-9). All were similarly well controlled, though the closed vial reactions went to higher conversion and molecular weight, presumably due to lower monomer evaporation. As expected, positive air pressure significantly affects the reaction; when a balloon of air was attached to the top of the reaction vial, the polymerization was inhibited $\left(M_{\mathrm{n}}=3.58 \mathrm{~kg} \mathrm{~mol}{ }^{-1}\right.$ after $\left.1 \mathrm{~h}\right)$ and less controlled $\left(M_{\mathrm{w}} / M_{\mathrm{n}}=1.35\right.$, Table S4, $\dagger$ entry 10$)$.

We then sought to compare the kinetics of the open vial polymerization to the corresponding air-free reaction (Fig. 4). A conversion correction was applied to the open vial polymerizations based on an estimation of monomer evaporation (see Section D in ESI $\dagger$ ). The air-free reaction had a 5 min induction period before displaying first order kinetics to $79 \%$ conversion in 1 hour. The open vial polymerization kinetics were run in triplicate to check for inconsistencies arising from oxygen scavenging. Indeed, in the first 20 minutes, there was variability in the GPC traces, from tailing to bimodality. There seemed to be a slight increase in induction period to around 10 minutes, though low molecular weight polymer was observed in 10 minutes in one of the trials. By 30 minutes, all traces had coalesced to monomodal, narrow peaks (Fig. S20 ${ }^{\dagger}$ ), and the molar masses matched very well with those from the air-free reaction (Fig. 4A).

The molar masses for both the air-free and open polymerizations increased approximately linearly with conversion (Fig. 4B). The air-free $M_{\mathrm{n}}$ values match very closely with the theoretical molar mass, whereas the open vial $M_{\mathrm{n}}$ values appear to be slightly higher. This observation could be due to some iniferter degradation at the beginning of the reaction as radicals react with dissolved oxygen, an error in the conversion correction, or both. MALDI-TOF mass spectrometry analysis of low molar mass samples verifies the expected polymer structure with the TTC moiety and two benzyl ester end groups $\left(\mathrm{Na}^{+}\right.$
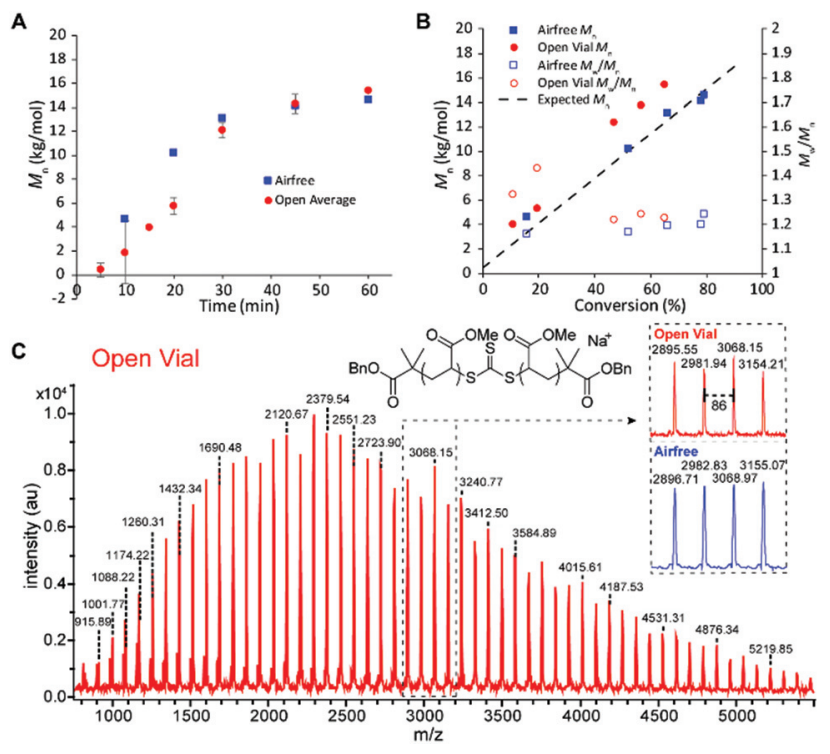

Fig. 4 Comparing the open vial polymerization to the analogous airfree reaction: (A) $M_{\mathrm{n}}$ increase over time (open vial polymerization average of three runs). (B) $M_{\mathrm{n}}$ versus conversion to show linear increase (note only one open vial trial shown, conversions for the open vial are estimated due to monomer evaporation). (C) MALDI-TOF analysis of low molecular weight samples to verify the TTC moiety and end groups remain intact for both cases.

adduct observed) and confirms the polymer structure is identical between the air-free and open vial polymerizations (Fig. 4C).

\section{Conclusions}

In this study, we report an iniferter photo-CRP that proceeds in completely open vials without any photocatalysts or additives. The polymerization is well controlled for acrylate monomers and displays living behavior through control over the molecular weight by adjusting the monomer:TTC ratio and chain extension over multiple cycles. Acrylamide monomers could also be polymerized in an uncapped vial, but with slightly less control. Oxygen tolerance is proposed to arise via the polymerizing through oxygen mechanism and careful experimental setup to limit the transport of oxygen in the air to the site of polymerization. After understanding the parameters that affect oxygen tolerance, the polymerization was able to be scaled up $4 \times$ to produce identical material to that of the smaller scale. Compared to the air-free reaction, the induction period may have increased from 5 to 10 minutes, but is still relatively short in comparison to the total reaction time of 60 minutes. Polymer of the same molar mass was produced in 1 hour for both the air-free and open vial cases and MALDI-TOF confirms that both have identical structures with the preservation of the TTC moiety and benzyl ester end groups. This system will help advance the understanding of oxygen tolerance in photocatalyst-free CRP and presents a very convenient platform to perform reversible deactivation radical 
polymerizations under ambient conditions for LAM in the future.

\section{Conflicts of interest}

The authors declare no competing financial interest.

\section{Acknowledgements}

The authors thank C. Perkinson and Prof. M. Bawendi for their help with the absolute irradiance measurements. We acknowledge the National Science Foundation (NSF CHE-1629358) for support of this work. This work was supported in part by the MRSEC Program of the NSF under award DMR 14-19807. J. R. L. gratefully acknowledges the National Institutes of Health for a postdoctoral fellowship (1F32GM126913-01A1).

\section{Notes and references}

1 K. Matyjaszewski and J. Xia, Chem. Rev., 2001, 101, 29212990.

2 E. M. Pelegri-O'Day and H. D. Maynard, Acc. Chem. Res., 2016, 49, 1777-1785.

3 D. F. Grishin and I. D. Grishin, Russ. J. Appl. Chem., 2011, 84, 2021-2028.

4 M. Chen, M. Zhong and J. A. Johnson, Chem. Rev., 2016, 116, 10167-10211.

5 J.-Y. Lee, J. An and C. K. Chua, Appl. Mater. Today, 2017, 7, 120-133.

6 M. Chen, M. J. MacLeod and J. A. Johnson, ACS Macro Lett., 2015, 4, 566-569.

7 M. Chen, Y. Gu, A. Singh, M. Zhong, A. M. Jordan, S. Biswas, L. T. J. Korley, A. C. Balazs and J. A. Johnson, ACS Cent. Sci., 2017, 3, 124-134.

8 V. A. Bhanu and K. Kishore, Chem. Rev., 1991, 91, 99-117.

9 S. C. Ligon, B. Husár, H. Wutzel, R. Holman and R. Liska, Chem. Rev., 2014, 114, 557-589.

10 J. Yeow, R. Chapman, A. J. Gormley and C. Boyer, Chem. Soc. Rev., 2018, 47, 4357-4387.

11 K. Matyjaszewski, S. Coca, S. G. Gaynor, M. Wei and B. E. Woodworth, Macromolecules, 1998, 31, 5967-5969.

12 S. R. Zavada, T. Battsengel and T. F. Scott, Int. J. Mol. Sci., 2016, 17, 195-221.

13 G. Gody, R. Barbey, M. Danial and S. Perrier, Polym. Chem., 2015, 6, 1502-1511.

14 F. M. Calitz, M. P. Tonge and R. D. Sanderson, Macromolecules, 2003, 36, 5-8.

15 J. Xu, K. Jung, A. Atme, S. Shanmugam and C. Boyer, J. Am. Chem. Soc., 2014, 136, 5508-5519.

16 S. Shanmugam, J. Xu and C. Boyer, Macromolecules, 2014, 47, 4930-4942.
$17 \mathrm{~J} . \mathrm{Xu}, \mathrm{K}$. Jung and C. Boyer, Macromolecules, 2014, 47, 4217-4229.

18 J. Xu, S. Shanmugam, H. T. Duong and C. Boyer, Polym. Chem., 2015, 6, 5615-5624.

19 S. Shanmugam, J. Xu and C. Boyer, J. Am. Chem. Soc., 2015, 137, 9174-9185

20 N. Corrigan, D. Rosli, J. W. J. Jones, J. Xu and C. Boyer, Macromolecules, 2016, 49, 6779-6789.

21 L. Yu, Y. Wei, Y. Tu, S. Lin, Z. Huang, J. Hu, Y. Chen, H. Qiao and W. Zou, J. Polym. Sci., Part A: Polym. Chem., 2018, 56, 2437-2444.

22 J. F. Quinn, L. Barner, C. Barner-Kowollik, E. Rizzardo and T. P. Davis, Macromolecules, 2002, 35, 7620-7627.

23 S. Muthukrishnan, E. H. Pan, M. H. Stenzel, C. BarnerKowollik, T. P. Davis, D. Lewis and L. Barner, Macromolecules, 2007, 40, 2978-2980.

24 T. G. McKenzie, Q. Fu, M. Uchiyama, K. Satoh, J. Xu, C. Boyer, M. Kamigaito and G. G. Qiao, Adv. Sci., 2016, 3, 1500394.

25 A. Anastasaki, V. Nikolaou, Q. Zhang, J. Burns, S. R. Samanta, C. Waldron, A. J. Haddleton, R. McHale, D. Fox, V. Percec, P. Wilson and D. M. Haddleton, J. Am. Chem. Soc., 2014, 136, 1141-1149.

26 L. Lu, H. Zhang, N. Yang and Y. Cai, Macromolecules, 2006, 39, 3770-3776.

27 H. Wang, Q. Li, J. Dai, F. Du, H. Zheng and R. Bai, Macromolecules, 2013, 46, 2576-2582.

28 H. Zhou and J. A. Johnson, Angew. Chem., Int. Ed., 2013, 52, 2235-2238.

29 T. G. McKenzie, Q. Fu, E. H. H. Wong, D. E. Dunstan and G. G. Qiao, Macromolecules, 2015, 48, 3864-3872.

$30 \mathrm{~J} . \mathrm{Xu}, \mathrm{S}$. Shanmugam, N. A. Corrigan and C. Boyer, in Controlled Radical Polymerization: Mechanisms, American Chemical Society, 2015, vol. 1187, pp. 247-267.

31 J. Yeow, O. R. Sugita and C. Boyer, ACS Macro Lett., 2016, 5, 558-564.

32 Q. Fu, K. Xie, T. G. McKenzie and G. G. Qiao, Polym. Chem., 2017, 8, 1519-1526.

33 J. Li, C. Ding, Z. Zhang, X. Pan, N. Li, J. Zhu and X. Zhu, Macromol. Rapid Commun., 2017, 38, 1600482.

34 See $\mathrm{ESI} \dagger$ for additional information.

35 R. W. Lewis, R. A. Evans, N. Malic, K. Saito and N. R. Cameron, Polym. Chem., 2018, 9, 60-68.

36 R. Bitar, P. Cools, N. De Geyter and R. Morent, Appl. Surf. Sci., 2018, 448, 168-185.

37 M. Donegan and D. P. Dowling, Surf. Coat. Technol., 2013, 234, 53-59.

38 F. L. Buchholz, in Industrial Polymers Handbook, 2001, vol. 1, pp. 565-585.

39 J. R. Rumble, Handbook of Chemistry and Physics. 2017-2018, CRC Press, Boca Raton, 98th edn, 2017.

40 R. Battino, T. R. Rettich and T. Tominaga, J. Phys. Chem. Ref. Data, 1983, 12, 163-178.

41 A. J. Gormley, J. Yeow, G. Ng, Ó. Conway, C. Boyer and R. Chapman, Angew. Chem., Int. Ed., 2018, 57, 1557-1562. 